\title{
Pneumonectomy in bronchial carcinoid tumors
}

\section{Pier Luigi Filosso ${ }^{1}$, Paraskevas Lyberis ${ }^{1}$, Francesco Guerrera ${ }^{1}$, Victor Auguste Nigra ${ }^{2 *}$, Paolo Olivo Lausi ${ }^{1}$, Enrico Ruffini ${ }^{1}$}

${ }^{1}$ Department of Surgical Sciences, Unit of Thoracic Surgery, University of Torino, Torino, Italy; ${ }^{2}$ Ospedale Regionale "Umberto Parini”" Viale Ginevra, 3, 11100 Aosta, Italy

Contributions: (I) Conception and design: PL Filosso, E Ruffini, PO Lausi; (II) Administrative support: VA Nigra; (III) Provision of study material: PL Filosso, VA Nigra, F Guerrera; (IV) Collection and assembly of data: PL Filosso, P Lyberis, VA Nigra; (V) Data analysis and interpretation: PL Filosso, F Guerrera, E Ruffini; (VI) Manuscript writing: All authors; (VII) Final approval of manuscript: All authors.

Correspondence to: Pier Luigi Filosso, MD. Department of Surgical Sciences, Unit of Thoracic Surgery, San Giovanni Battista Hospital, University of Torino, Corso Dogliotti, 14 10126, Torino, Italy. Email: pierluigi.filosso@unito.it.

\begin{abstract}
Bronchial carcinoids (BCs) are a part of the Lung Neuroendocrine Tumors group, and account for approximately $0.4 \%$ to $3 \%$ of all lung malignancies in adults. They have been classified as typical (TC) and atypical carcinoid (AC), according to their different histological and biological characteristics. The anatomic BC distribution is slightly different: in approximately $85 \%$ of cases TC is centrally located (typically defined as visible by the bronchoscopy), versus $15 \%$ only AC. Surgery (with the aim of a complete tumor resection, preserving as much lung parenchyma as possible, along with a systematic lymphadenectomy) represents the standard of care for BC's treatment. In recent years, and based on different clinical experiences, the role of pneumonectomy in central tumors has been deeply revised, following the increasingly frequent use of bronchoplasty and sleeve lobectomy. Bronchial sleeve or sleeve lobectomy demonstrated to have the same survival of classic anatomical surgical resections offered for other primary lung cancers. The absence of neoplastic cells in the bronchial resection margins intraoperative histological confirmation represents the necessary condition to confirm the oncological radicality of these procedures. Furthermore, following the recent guidelines, any lung resection for BCs must necessarily be accompanied by a systematic lymphadenectomy, as in the case of primary lung cancers. Aim of this article is to review the indications for surgical resections, especially emphasizing the role of limited resections and the possible endobronchial treatment for centrally located tumors.
\end{abstract}

Keywords: Bronchial carcinoid (BC); surgery; pneumonectomy; bronchial sleeve; sleeve lobectomy; guidelines

Received: 14 April 2020; Accepted: 24 September 2020; Published: 10 July 2021.

doi: 10.21037/shc-2019-rpts-23

View this article at: http://dx.doi.org/10.21037/shc-2019-rpts-23

\section{Introduction}

Bronchial carcinoids (BCs) are relatively rare lung neoplasms of neuroendocrine origin, accounting for $0.4 \%$ to $3 \%$ of all resected primary lung cancers, and about $25 \%$ of all carcinoids (1). They have been historically classified, by pathologic characteristics, as typical carcinoid (TC; $<2$ mitoses $/ 2 \mathrm{~mm}^{2}$ of tumor) and atypical carcinoid (AC; 2 to 10 mitoses, presence of necrosis and/or architectural disruption) (2) (Table 1). This pathological classification demonstrated to be very effective since it enhanced reproducibility between Pathologists, as well as prognostic differentiation in patients clinical outcome (Table 2). Prognosis implies different clinical/therapeutical options, especially when BCs are compared to other Non-Small-Cell Carcinomas. Despite their characteristic indolent behavior, BCs have to be considered as malignant tumors, because

* Dr. Victor Auguste Nigra took part to this study when he worked at the Unit of Thoracic Surgery, University of Torino, Torino, Italy 
Table 1 Bronchial carcinoids: pathological characteristics

\begin{tabular}{lll}
\hline & TC & AC \\
\hline Mitoses (per 10 HPFs) & $<2$ & $2-10$ \\
Necosis & No & Yes (punctate) \\
Shape & Round, oval, spindled & Round, oval, spindled \\
Median age & $40-50 y$ & $50-60 y$ \\
Association with smoking & No & Yes \\
\hline
\end{tabular}

Table 2 Bronchial carcinoids: clinical characteristics

\begin{tabular}{lll}
\hline & TC & AC \\
\hline Central/peripheral ratio & $3: 1$ & $3: 1$ \\
Stage I & $87 \%$ & $43 \%$ \\
Advanced Stages & $10 \%$ & $28 \%$ \\
Extrathoracic lesions & $3 \%$ & $20 \%$ \\
FDG uptake at PET scan & Low & Low/moderate \\
\hline
\end{tabular}

they may invade or metastatize.

BCs have an equal gender and a wide age distribution. The chance to have an AC is about $25 \%$ in patients older than 50 years, and less then $10 \%$ in those younger than $30(3,4)$. A peripheral tumor location is generally the prerogative of $\mathrm{AC}$, while most central lesions (usually detectable by bronchoscopy) are TCs.

From the clinical point of view, in approximately $30 \%$ of cases the tumor is asymptomatic; cough, hemoptysis and recurrent pneumonia are the commonest symptoms in centrally located one (5-7). It is not unusual a prolonged medical treatment for unresolved pulmonary infection or asthma, conditions that may determine a delayed diagnosis.

BCs' standard of care is surgical resection, with the surgical approach depending on tumor's size, location and histology. TCs have an excellent prognosis after a complete resection: 5 -year survival rates may vary between $87 \%$ to $100 \%$ and 10 -year survival rates between $87 \%$ and $80 \%$, according to the different clinical series (8-11). ACs have a poorer 5 and 10-year survival rates, ranging between $95 \%$ and $40 \%$ (5-year) and $56 \%$ to $35 \%$ (10-year) (12-15).

\section{Surgical approach}

In January 1984 , during the $20^{\text {th }}$ Society of Thoracic Surgeons (STS) Annual Meeting, Dr. Wilkins and Coll. reported on 111 BCs operated between 1931 and 1981 at the Massachusetts General Hospital (16). The Authors splitted their series into 2 periods, with 1963 as the cut-off year. Some interesting conclusions resulted from the paper and its discussion: (I) the number of pneumonectomy/ bilobectomy significantly decreased in the second period of their series; (II) many sleeve bronchial resections were performed after 1963; (III) some tumor excision without any pulmonary resections were firstly described; (IV) lobectomy rather than pneumonectomy became the standard surgical approach for central tumors; (V) the importance of routine lymph node dissection was emphasized, by recognizing that even TCs might have metastasized to lymph nodes, that are not grossly appreciated.

Current International Guidelines and State of the Art articles (17-19) still incorporate these suggestions. From a practical point of view, surgical approach to BCs is derived from the surgical principles for localised primary lung cancers.

Complete anatomical resections (e.g., segmentectomy or lobectomy) with systematic lymphadenectomy are recommended for peripheral lesions. The extent of lymph node resection must conform to the IASLC recommendations: this involves a minimum of six nodes/ stations, three of which should be mediastinal, also including the subcarinal station (20). Peripheral ACs may have an increased risk of local recurrence when a nonanatomical sublobar resection is performed (14). 

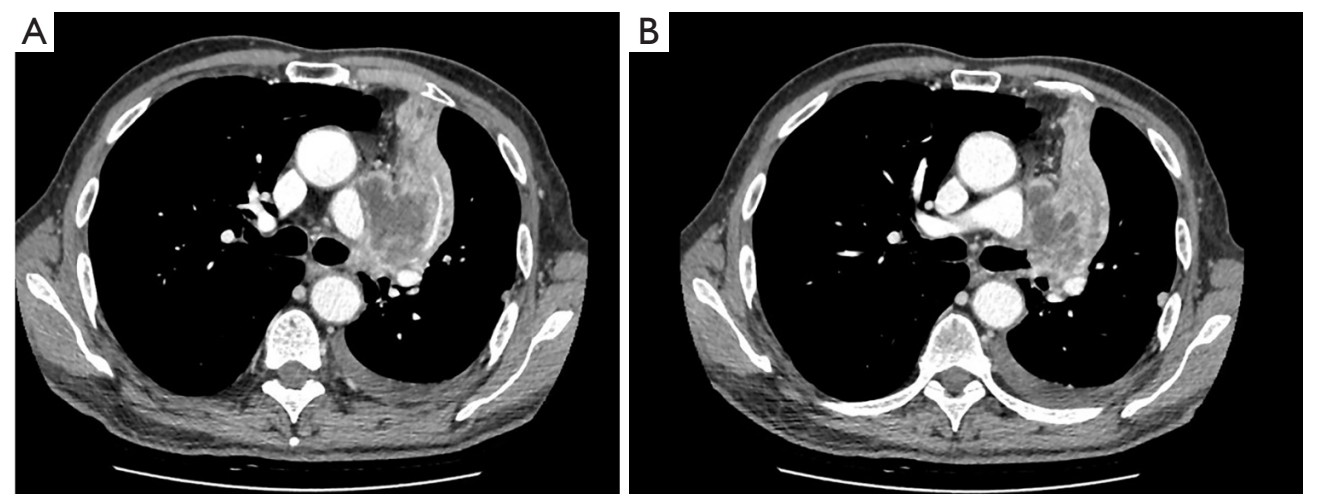

Figure 1 Left side N2 centrally-located TC with destroyed lung (A); the tumor originates from the left main bronchus (B).

In case of centrally located tumors (especially TCs), whenever possible, bronchial sleeve resection (without lung parenchyma sacrifice) or sleeve lobectomy (both procedures with intraoperative frozen section of the resection margins) should be carried out in preference to pneumonectomy $(21,22)$. The need to avoid pneumonectomy gets more weight when we consider that central TC affects preferentially young people.

When distant pneumonitis and/or destroyed lung parenchyma are present (Figure 1), an initial local endobronchial resection to disobliterate the airway may be performed before re-assessment for lung parenchymalsparing surgery.

Systematic nodal dissection should be done, since lymph node metastases may be present in up to $25 \%$ of cases in $\mathrm{TC}$ and $>50 \%$ in $\mathrm{AC}(9,22,23)$.

Several clinical series published in the late 90 s and early 2000s stigmatized this different surgical approach. Filosso et al. (5) reported 126 BCs operated between 1977 and $1999 ; 103(82 \%)$ of them were centrally located and pneumonectomy was performed in 15 cases, only (11.9\%) (9 of them performed before the 1990s). The Authors described also 4 sleeve lobectomies, 17 bilobectomies and 3 bronchial sleeve resections without lung parenchyma sacrifice.

Cardillo and Coll. (24) published about 163 patients treated from January 1990 to April 2002; operations included 12 pneumonectomies (4.5\%), 21 bilobectomies and 8 sleeve lobectomies in central tumors.

García-Yuste et al. (17) on behalf of the Spanish MultiCentric Study of Neuroendocrine Tumours of the Lung for the Spanish Society of Pneumonology and Thoracic Surgery, reported about 661 patients treated from 1980 and 2002 in Spain. The Authors performed 9 bronchial sleeve resections, 57 sleeve lobectomy and 63 (11\%) pneumonectomies and did not find any difference in survival between patients receiving lobectomy or pneumonectomy and those in whom a sleeve resection was performed, both in TCs and ACs.

Rea and Coll. (25) splitted their experience with 252 patients into 2 groups: patients operated between 1968 and 1989 (Group A) and those treated between 1990 and 2005 (Group B). Overall, 18 bilobectomies, 10 pneumonectomies and 76 sleeve or bronchoplastic resections were performed. From the surgical point of view, in Group B the number of sleeve resections significantly increased $(2.7 \%$ versus $20.4 \% ; \mathrm{P}=0.0001)$ while the number of pneumonectomy was significantly reduced $(7.2 \%$ versus $1.4 \% ; \mathrm{P}=0.01)$. This paper, with a large series of patients covering a very long period of time, still emphasizes the evolution of surgical strategy for BCs.

In a paper by Filosso et al. (26) based on the European Society of Thoracic Surgeon (ESTS) Neuroendocrine Tumours Working Group (NET-WG) Database, 1,109 TC patients from 17 institutions worldwide were studied. Centrally located tumors were 457 (61\%); bilobectomy was performed in 82, pneumonectomy in $29(2.6 \%)$ and sleeve resections in $77(6.9 \%)$ cases, respectively. The results of this study represent the most recent international experience and still confirm the attitude of avoiding pneumonectomy for interventions with less parenchymal sacrifice.

\section{When pneumonectomy is needed}

Currently, few are the indications for pneumonectomy in BCs, apart from vascular accidents or other intraoperative surgical complications: (I) central tumors with distant severe pneumonitis or destroyed lung; (II) central or (III) 

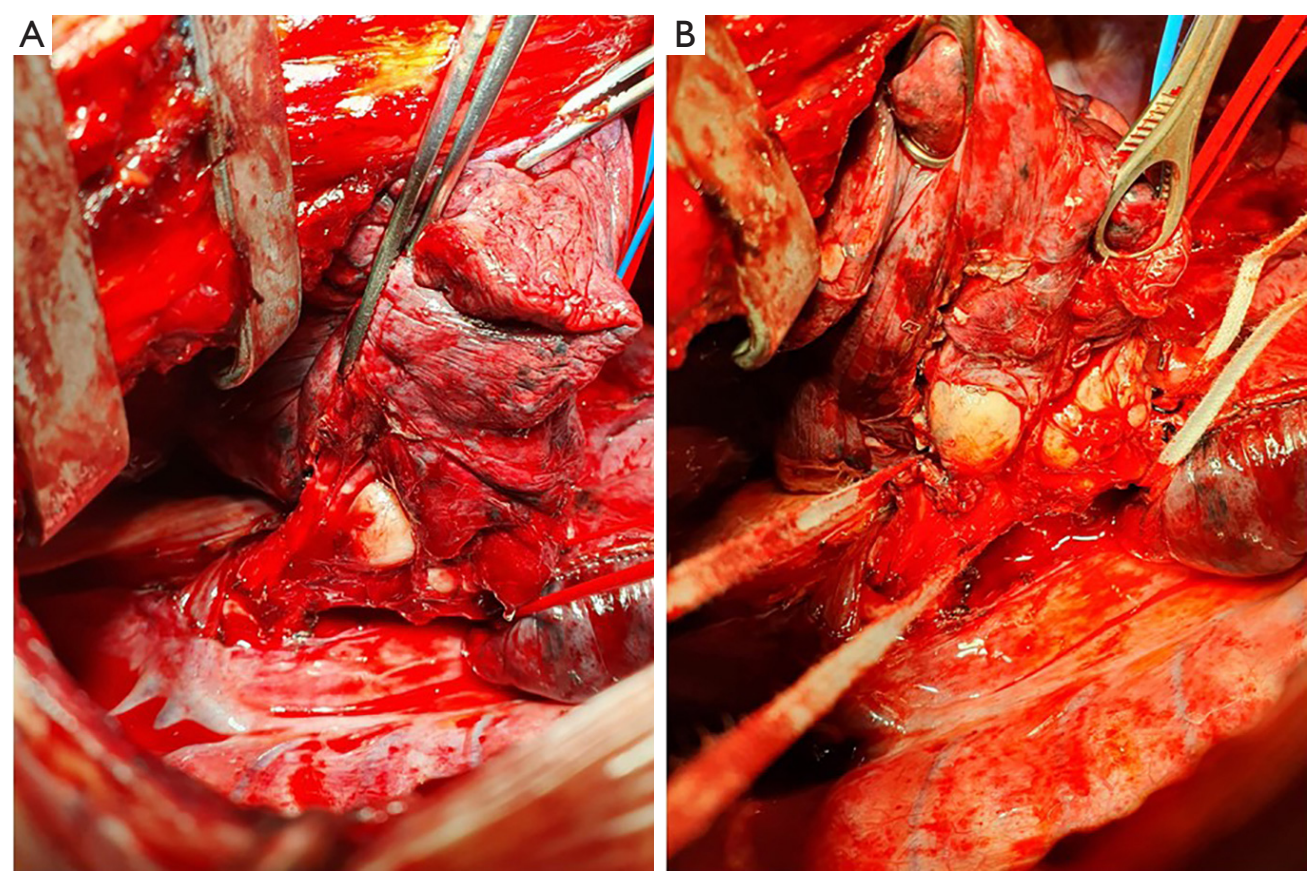

Figure 2 Right large central TC (for description see the text).

very large tumors in whom bronchoplastic procedure is not deemed feasible; (IV) tumor recurrence after bronchial sleeve resection/lobectomy.

Figure 1 shows a classic example of the first clinical condition. An endobronchial centrally-located TC originating from the left main bronchus, associated with mediastinal lymphnodal enlargement, caused a major atelectasis of the lung, especially in the left upper lobe. Sleeve bronchial resection was impossible, due to the endobronchial extension of the tumor (confirmed by bronchial frozen sections). Intrapericardial left pneumonectomy was therefore necessary.

Patient in Figure 2 presents with an hilar large TC, characterized by both endo and exo-bronchial growth (A). Tumor extension, which involved both the main and intermediate bronchus (B) did not allowed a limited resection, and a right pneumonectomy was therefore performed.

Finally, Konstantinidis et al. (27) recently described a rare case of postpneumonectomy-like syndrome (resulting in a severe lung volume loss with an excessive mediastinal shift and herniation of the contralateral lung into the contralateral hemithorax, mimicking the classical clinical condition observed in a postpneumonectomy syndrome some years after pneumonectomy), caused by an AC with purely intraluminal growth. A left pneumonectomy was performed, since a parenchymal-sparing surgery was deemed oncologically not radical because preoperative chest CT scan showed infiltration of the periphery of the left main bronchus, subsequently confirmed by final pathology.

\section{Alternatives to pneumonectomy}

If surgical resection is traditionally the preferred approach for patients with BCs, in very selected cases, laser endobronchial treatment (EBT) has shown promising results (28-30). EBT may have other important advantages, such as the involved bronchus deobstruction, with the theoretical resolution of the consequent obstructive pneumonia. This may mean an improvement in patient's clinical symptoms, but also the theoretical possibility of performing a less extensive resection.

With the intent to bring order to EBT indications, a systematic literature review was recently reported (31). Results showed that: (I) tumor histology, (II) the presence of lymph-nodal involvement, (III) tumor location and (IV) tumor size were identified as negative prognostic factors. For patients with a more favourable prognosis, tumor location and its diameter may influence the optimal treatment strategy, in the sense that small central tumors, with an exclusive intraluminal growth and without signs of lymphnodal metastases can benefit positively from a 
minimally-invasive approach (EBT or pure bronchoplastic sleeve resection).

Since challenging complication may occur during/after EBT (e.g., important bleeding, bronchospasm, stricture of the bronchial tree and vocal cord palsy) (32), this procedure should be performed in highly specialized centers, with dedicated interventional pulmonologists, anesthesiologists and thoracic surgeons (30).

\section{Conclusions}

In conclusion, surgery remains the gold standard for BCs' treatment. Anatomical resections along with systematic lymphadenectomy are recommended by the current International Guidelines. With the aim to avoid extensive parenchymal resections, the number of performed bronchial sleeve and sleeve lobectomy is dramatically increased in recent decades. Such procedures are now the standard of care for central BCs. Pneumonectomy is currently reserved for those few cases of tumors with distant severe pneumonitis or destroyed lung, for those in whom bronchoplastic procedure is not deemed feasible or in case of tumor recurrence after bronchial sleeve resection/ lobectomy.

Laser endobronchial treatment (EBT) sometimes represents an initial treatment, with bronchial deobstruction with the theoretical resolution of the consequent obstructive pneumonia and the possibility to perform a less extensive lung resection.

\section{Acknowledgments}

Funding: None.

\section{Footnote}

Provenance and Peer Review: This article was commissioned by the Guest Editors (Lorenzo Spaggiari and Luca Bertolaccini) for the series "The Role of Pneumonectomy in Thoracic Surgery in The Third Millennium" published in Shanghai Chest. The article has undergone external peer review.

Conflicts of Interest: All authors have completed the ICMJE uniform disclosure form (available at http://dx.doi. org/10.21037/shc-2019-rpts-23). The series "The Role of Pneumonectomy in Thoracic Surgery in The Third Millennium" was commissioned by the editorial office without any funding or sponsorship. The authors have no other conflicts of interest to declare.

Ethical Statement: The authors are accountable for all aspects of the work in ensuring that questions related to the accuracy or integrity of any part of the work are appropriately investigated and resolved.

Open Access Statement: This is an Open Access article distributed in accordance with the Creative Commons Attribution-NonCommercial-NoDerivs 4.0 International License (CC BY-NC-ND 4.0), which permits the noncommercial replication and distribution of the article with the strict proviso that no changes or edits are made and the original work is properly cited (including links to both the formal publication through the relevant DOI and the license). See: https://creativecommons.org/licenses/by-nc-nd/4.0/.

\section{References}

1. Escalon J, Detterbeck F. Carcinoid tumors. In: Shields T, LoCicero JI, Reed C, Feins R (eds). General Thoracic Surgery. 7th edition. Philadelphia: Lippincott Wiliams \& Wilkins; 2009:1539-54.

2. Travis WD, Rush W, Flieder DB, et al. Survival analysis of 200 pulmonary neuroendocrine tumors with clarification of criteria for atypical carcinoid and its separation from typical carcinoid. Am J Surg Pathol 1998;22:934-44.

3. Hurt R, Bates M. Carcinoid tumours of the bronchus: a 33-year experience. Thorax 1984;39:617-23.

4. Bertelsen S, Aasted A, Lund C, et al. Bronchial carcinoid tumours. A clinicopathologic study of 82 cases. Scand J Thorac Cardiovasc Surg 1985;19:105-11.

5. Filosso PL, Rena O, Donati G, et al. Bronchial carcinoid tumors: surgical management and long-term outcome. J Thorac Cardiovasc Surg 2002;123:303-9.

6. Litvak A, Pietanza MC. Bronchial and Thymic Carcinoid Tumors. Hematol Oncol Clin North Am 2016;30:83-102.

7. Filosso PL, Guerrera F, Thomas P, et al. Management of bronchial carcinoids: international practice survey among the European Society of Thoracic Surgeons. Future Oncol 2016;12:1985-99.

8. Filosso PL, Oliaro A, Ruffini E, et al. Outcome and prognostic factors in bronchial carcinoids: a single-center experience. J Thorac Oncol 2013;8:1282-8.

9. Lim E, Yap YK, De Stavola BL, et al. The impact of stage and cell type on the prognosis of pulmonary neuroendocrine tumors. J Thorac Cardiovasc Surg 
2005;130:969-72.

10. Wu BS, Hu Y, Sun J, et al. Analysis on the characteristics and prognosis of pulmonary neuroendocrine tumors. Asian Pac J Cancer Prev 2014;15:2205-10.

11. Cattoni M, Vallières E, Brown LM, et al. Improvement in TNM staging of pulmonary neuroendocrine tumors requires histology and regrouping of tumor size. J Thorac Cardiovasc Surg 2018;155:405-413.

12. Johnson R, Trocha S, McLawhorn M, et al. Histology, not lymph node involvement, predicts long-term survival in bronchopulmonary carcinoids. Am Surg 2011;77:1669-74.

13. Daddi N, Schiavon M, Filosso PL, et al. Prognostic factors in a multicentre study of 247 atypical pulmonary carcinoids. Eur J Cardiothorac Surg 2014;45:677-86.

14. Filosso PL, Rena O, Guerrera F, et al. Clinical management of atypical carcinoid and large-cell neuroendocrine carcinoma: a multicentre study on behalf of the European Association of Thoracic Surgeons (ESTS) Neuroendocrine Tumours of the Lung Working Group. Eur J Cardiothorac Surg 2015;48:55-64.

15. Marciello F, Mercier O, Ferolla P, et al. Natural History of Localized and Locally Advanced Atypical Lung Carcinoids after Complete Resection: A Joined French-Italian Retrospective Multicenter Study. Neuroendocrinology 2018;106:264-273.

16. Wilkins EW, Grillo HC, Moncure AC, et al. Changing times in surgical management of bronchopulmonary carcinoid tumor. Ann Thorac Surg 1984;38:339-44.

17. García-Yuste M, Matilla JM, Cueto A, et al. Typical and atypical carcinoid tumours: analysis of the experience of the Spanish Multi-centric Study of Neuroendocrine Tumours of the Lung. Eur J Cardiothorac Surg 2007;31:192-7.

18. Caplin ME, Baudin E, Ferolla P, et al. Pulmonary neuroendocrine (carcinoid) tumors: European Neuroendocrine Tumor Society expert consensus and recommendations for best practice for typical and atypical pulmonary carcinoids. Ann Oncol 2015;26:1604-20.

19. Baudin E, Hayes AR, Scoazec JY, et al. Unmet Medical Needs in Pulmonary Neuroendocrine (Carcinoid) Neoplasms. Neuroendocrinology 2019;108:7-17.

20. Goldstraw P. International Association for the Study of Lung Cancer Staging Manual in Thoracic Oncology. Florida, USA: Editorial Rx Press 2009.

21. Detterbeck FC. Management of carcinoid tumors. Ann Thorac Surg 2010;89:998-1005.

22. Daddi N, Ferolla P, Urbani M, et al. Surgical treatment of neuroendocrine tumors of the lung. Eur J Cardiothorac Surg 2004;26:813-7.

23. Hage R, de la Rivière $A B$, Seldenrijk CA, et al. Update in pulmonary carcinoid tumors: a review article. Ann Surg Oncol 2003;10:697-704.

24. Cardillo G, Sera F, Di Martino M, et al. Bronchial carcinoid tumors: nodal status and long-term survival after resection. Ann Thorac Surg 2004;77:1781-5.

25. Rea F, Rizzardi G, Zuin A, et al. Outcome and surgical strategy in bronchial carcinoid tumors: single institution experience with 252 patients. Eur J Cardiothorac Surg. 2007;31:186-91.

26. Filosso PL, Guerrera F, Evangelista A, et al. Prognostic model of survival for typical bronchial carcinoid tumours: analysis of 1109 patients on behalf of the European Association of Thoracic Surgeons (ESTS) Neuroendocrine Tumours Working Group. Eur J Cardiothorac Surg 2015;48:441-7.

27. Konstantinidis AK, Vitsas VV, Tatsis K, et al. Postpneumonectomy-like syndrome due to bronchial carcinoid: a unique case report. BMC Pulm Med 2019;19:44.

28. Dalar L, Ozdemir C, Abul Y, et al. Endobronchial Treatment of Carcinoid Tumors of the Lung. Thorac Cardiovasc Surg 2016;64:166-71.

29. Pikin O, Ryabov A, Sokolov V, et al. Two-Stage Surgery Without Parenchyma Resection for Endobronchial Carcinoid Tumor. Ann Thorac Surg 2017;104:1846-51.

30. Reuling EMBP, Dickhoff C, Plaisier PW, et al. Endobronchial Treatment for Bronchial Carcinoid: Patient Selection and Predictors of Outcome. Respiration 2018;95:220-7.

31. Reuling EMBP, Dickhoff C, Plaisier PW, et al. Endobronchial and surgical treatment of pulmonary carcinoid tumors: A systematic literature review. Lung Cancer 2019;134:85-95.

32. Brokx HA, Paul MA, Postmus PE, et al. Long-term follow-up after first-line bronchoscopic therapy in patients with bronchial carcinoids. Thorax 2015;70:468-72.

doi: 10.21037/shc-2019-rpts-23

Cite this article as: Filosso PL, Lyberis P, Guerrera F, Nigra VA, Lausi PO, Ruffini E. Pneumonectomy in bronchial carcinoid tumors. Shanghai Chest 2021;5:31. 